\title{
O BRINCAR E AS BRINCADEIRAS COMO FERRAMENTAS INDISPENSÁVEIS PARA A MEDIAÇÃO DO ENSINO: TRABALHANDO LUDICIDADE E MATEMÁTICA NA EDUCAÇÃO INFANTIL
}

Francineide Braga Bezerra, Universidade Federal de Campina Grande (UFCG),

Francineide232@gmail.com

Cicera Nayara de Oliveira Silva, Universidade Federal de Campina Grande (UFCG), ciceranayaraaurora@gmail.com

Danilo de Sousa Cezario, Universidade Federal de Campina Grande (UFCG), danilomotos@hotmail.com

\section{RESUMO}

Esse artigo tem por objetivo explanar a utilização do lúdico como mediador dos conhecimentos teóricos para crianças na Educação Infantil, na qual o brincar surge como aporte de mediação dos conteúdos matemáticos. Nesse sentido, a roda de conversação e os jogos lúdicos perpassam as barreiras interiorizadas na mentalidade das crianças frente aos receios da então "temida matemática", minimizando as disparidades entre aluno/aluno e aluno/professor. Como aporte teórico, trabalhou-se com o lúdico e o ensino de matemática nos anos iniciais, bem como as conversações e as rodas de conversas nos discursos de Reame, Canal, Cruz, Gostenski, Barbieri, Camargo. Nessa perspectiva, o artigo apresenta a relevante importância de um trabalho ludopedagogico, em que o docente utiliza da ferramenta lúdica para mediar o conhecimento na disciplina de matemática ampliando os conhecimentos dos alunos frente as dificuldades. Sendo assim, o papel do professor é de demonstrar que o brincar e as brincadeiras são "ingredientes" essenciais para contribuição humanística e dos valores sociais e morais.

\section{PLAYING AND PLAYING AS INDISPENSABLE TOOLS FOR THE MEDIATION OF TEACHING: WORKING LUDICITY AND MATHEMATICS IN CHILD EDUCATION}

\begin{abstract}
This paper aims to explain the use of ludic language as a mediator of theoretical knowledge for children in Early Childhood Education, in which playing arises as a contribution to mediation of mathematical contents. That way, conversation circles and games go beyond the the children's mind barriers regarding the "dreaded Mathematics", minimizing disparities between student/student and student/teacher. As a theoretical contribution, we have worked with ludic language and teaching Mathematics in the early years, as well as conversations and the conversation circles based on the works of Reame, Canal, Cruz, Gostenski, Barbieri, Camargo. In this perspective, this paper presents
\end{abstract}


the relevant importance of a ludic and pedagogical work, in which the teacher uses ludic tools to mediate knowledge in Mathematics to expand students' knowledge in the face of difficulties. Thus, the role of the teacher is to demonstrate that the playing is an essential "ingredient" for humanistic contribution and social and moral values.

KEYWORDS: Play, Ludic and Pedagogical, Mathematics.

\title{
EL BRINCAR Y LAS BRINCADERAS COMO HERRAMIENTAS INDISPENSABLES PARA LA MEDIACIÓN DE LA ENSEÑANZA: TRABAJANDO LUDICIDAD Y MATEMÁTICA EN LA EDUCACIÓN INFANTIL
}

\begin{abstract}
RESUMEN
Este artículo tiene por objetivo explicar la utilización del lúdico como mediador de los conocimientos teóricos para niños en la Educación Infantil, en la cual el jugar surge como aporte de mediación de los contenidos matemáticos. En ese sentido, la rueda de conversación y los juegos lúdicos atravesan las barreras interiorizadas en la mentalidad de los niños frente a los temores de la "temida matemática", minimizando las disparidades entre alumno / alumno y alumno / profesor. Como aporte teórico, se trabajó con el lúdico y la enseñanza de matemáticas en los años iniciales, así como las conversaciones y las ruedas de conversaciones en los discursos de Reame, Canal, Cruz, Gostenski, Barbieri, Camargo. En esta perspectiva, el artículo presenta la relevante importancia de un trabajo ludopedagogico, en el que el docente utiliza la herramienta lúdica para mediar el conocimiento en la disciplina de matemáticas ampliando los conocimientos de los alumnos frente a las dificultades. Por lo tanto, el papel del profesor es demostrar que el juego y los juegos son "ingredientes" esenciales para la contribución humanística y los valores sociales y morales.
\end{abstract}

PALABRAS CLAVE: Jugar, Ludicopedagógico, Matemáticas.

\section{INTRODUÇÃO}

Este artigo demonstra a importância de trabalhar com a ludicidade representada através dos jogos, para mediar a compreensão e o entendimento das crianças nas aulas de matemática na Educação Infantil. Tal trabalho foi elaborado para fins avaliativos da disciplina Fundamentos e Metodologias do Ensino da Matemática, sob a orientação do professor Danilo de Sousa Cezario, no curso de Licenciatura plena em Pedagogia, da Unidade acadêmica de Educação do Centro de Formação de Professores da Universidade Federal de Campina Grande, Campus de Cajazeiras - PB. 
As aulas de Matemática sempre foram vistas por muitos alunos como uma disciplina difícil e que despertar temor, pois, estes a compreendem somente como pura memorização de fórmulas e resolução de cálculos. Para que esse paradigma seja quebrado, ainda nos primeiros contatos entre professores/matemática/alunos é preciso buscar a mediação de forma dinâmica e prazerosa, na qual o brincar e a brincadeira serão ferramentas que permitam a construção de um elo entre a teoria e a prática por meio do lúdico.

Diante disso, percebe-se que é viável minimizar traumas e receios perante a matemática, que assim como o português, faz parte da vivência diária do ser humano. Pode-se notar a importância do docente de matemática em sua pratica pedagógica trabalhar atividades para os alunos da Educação Infantil, de forma lúdica e prazerosa.

Durante a temática abordada, vê-se a relevância de ser utilizado o ludicopedagógico nesse processo juntamente com os jogos e brincadeiras, os quais contribuem para o desempenho do aprendizado e na vontade de conhecer a matemática escolar.

Haja vista, que são inúmeros questionamentos e discussões a respeito da "fórmula ideal" de ensinar a matemática, pretende-se estimular as crianças para que aprendam de maneira prazerosa e divertida, oportunizando um amplo processo de ensino-aprendizagem. Propicia-se, ainda, suporte para os professores repensarem novos saberes e metodologias de ensino ao confeccionarem jogos e brincadeiras, instigando os alunos a desenvolverem novas habilidades e estimulando as suas criatividades.

\section{O BRINCAR NA EDUCAÇÃO INFANTIL}

A brincadeira oportuniza ao educando um amplo leque de saberes, bem como a construção de novos conhecimentos de maneira livre e espontânea. Dessa maneira, o brincar fomenta o desenvolvimento das capacidades e habilidades inerentes a cada criança. Por meio do brincar, a criança deixa transparecer seu lado sentimental e emocional, uma vez que sofre influências em sua vivência escolar e na convivência em grupo. Nesse sentido, Maranhão (2004) destaca que: 
É por meio da brincadeira que a criança efetua suas primeiras grandes realizações culturais e psicológicas e que expressa seus sentimentos e pensamentos. A criança utiliza a brincadeira para expressar seus sentimentos, ela não escolhe uma brincadeira por acaso, ela reflete suas inquietações, seus problemas. No momento que a criança brinca, ela pode revelar o que está acontecendo na sua mente. O brinquedo estimula a representação da realidade ao representá-la ela estará vivendo algo ou alguma coisa situação remota ou irreal naquele momento (p.17).

Nessa compreensão, a criança faz uso das brincadeiras para dar sentido e significado às situações vivenciadas cotidianamente, as quais influenciam nos aspectos de relacionamento com os demais indivíduos. Nesse contexto, pode-se destacar a relevância do brincar no processo de ensino-aprendizagem. Sobre isso, Kishimoto (1999) aponta que

O brinquedo coloca a criança na presença de reproduções: tudo o que existe no cotidiano, a natureza e as construções humanas. Pode-se dizer que um dos objetivos do brinquedo é dar a criança um substituto dos objetos reais, para que possa manipulá-los (p.21).

Nessa linha de pensamento, a brincadeira possibilita ao educador um mecanismo capaz de modificar a realidade na qual se encontra inserido. Assim, enquanto a criança brinca é possível perceber seus avanços e sua amplitude na aprendizagem, uma vez que, influenciará na aquisição de conhecimentos de toda a turma. Dessa maneira, é imprescindível ao profissional da educação oportunizar aulas dinâmicas para se dar um maior aprendizado ao discente, como também, uma ampliação do raciocínio matemático. Nessa assertiva Smole (2000) afirma que,

A criança desenha e cria porque brinca. Para ela, a mesma concentração de corpo exigida ao brincar aparece no desenhar, nesse sentido o corpo inteiro está presente na ação, concentrado na pontinha do lápis, e aponta do lápis funciona como uma ponte de comunicação entre o corpo e o papel. Sabemos também que o desenho para registrar uma vivencia é muito significativo para a criança na Educação Infantil porque é sua primeira linguagem de expressão e comunicação de suas percepções do mundo (p.17).

Nessa perspectiva, percebem-se os inúmeros benefícios obtidos frente ao ato de brincar para a construção do conhecimento. Vale destacar a relevância de a criança ter a liberdade de buscar e solucionar problemas/situações cotidianas para enriquecer os saberes referentes à matemática. 
Diante do exposto, a brincadeira proporciona às crianças um largo entendimento e amplia sua capacidade de internalização de regras e dos valores necessários para uma vida em sociedade, bem como possibilita a aquisição de um notório amadurecimento em relação aos elementos da cognição.

\section{CONTRIBUIÇÕES DO LÚDICO NO ENSINO DA MATEMÁTICA}

O papel do professor nesse processo é planejar a ludicidade nas aulas de matemáticas com atividades que minimizem as dificuldades dos alunos, fornecendo através do brincar uma ampla aquisição dos conhecimentos de maneira prazerosa e proveitosa.

O brincar e a brincadeira estejam envolvidos com a realidade das crianças e sejam meios facilitadores para se ensinar e discutir conteúdos a serem estudados. Assim entende-se que

Para que a aprendizagem ocorra de fato, o professor precisa apresentar possibilidades e recursos, e o lúdico é uma alternativa que pode ser usada para estimular de forma prazerosa a aprendizagem, porem o professor precisa planejar levando em conta os objetivos pretendidos ao utilizar jogos na aprendizagem (CANAL; CRUZ; et al. 2013, p.4).

Nesse sentido, o docente deve se manter focado com essa articulação, envolvendo teoria e prática perpassando pelo lúdico. Visto como indispensável para a inovação das aulas de matemática, o lúdico possibilita ao educador uma ampla visibilidade em relação às metodologias e ao processo de ensino e aprendizagem.

É importante salientar que o professor antes de expor aos alunos essa nova abordagem de estudo através da ludicidade, deve sempre fazer um mapeamento das dificuldades deles e assim, estabelecer planos e metas, utilizando as brincadeiras como mecanismo da aprendizagem. O professor precisa apresentar o lúdico como algo que possui uma finalidade neste contexto. Aprender matemática de maneira leve e dinâmica é um grande desafio que tem que ser rompido. Nesse sentido, é interessante o que Pinto (2003) nos diz:

O espaço lúdico não precisa ficar restrito a quatro paredes, ao contrário, deve fluir por todo o ambiente, dentro e fora das classes. Um dos objetivos desse espaço é favorecer o encontro de crianças, para brincar, jogar, fazer amigos, propiciar a convivência alegre e descontraída dos frequentadores.(p. 65). 
Nesse diapasão, os instrumentos pedagógicos, a exemplo dos jogos matemáticos, servem de estímulos e apoio na criatividade dos alunos, proporcionando participação de todos, assim como estimulando a convivência em grupo e, posteriormente, fortalecendo os vínculos sociais entre as crianças dentro e fora da sala de aula. Sendo assim, Grando (2004) realça que:

O jogo em seu aspecto pedagógico apresenta-se produtivo ao professor que busca nele um aspecto instrumentador e, portanto, facilitador na aprendizagem de estruturas matemáticas, muitas vezes de difícil assimilação, e também produtivo ao aluno, que desenvolveria sua capacidade de pensar, refletir, analisar, compreender conceitos matemáticos, levantar hipóteses, testá-las e avaliá-las (investigação matemática), com autonomia e cooperação (p. 26).

Assim, através de aulas lúdicas a criança passa a criar estratégias de vivências e convivências, desenvolvendo suas capacidades cognitivas, afetivas e sociais, bem como, exercitar sua imaginação e criatividade diante da reflexão e compreensão dos conceitos matemáticos.

O lúdico não consiste somente no brincar sem intencionalidade, objetivos e metas, ele contribui no desenvolvimento intelectual e social da criança, instigando neles o gosto em conhecer e apreender os elementos que compõe a matemática, os quais vão estar inseridos diariamente em suas vivências escolares, familiares, como também, na convivência no meio social.

\section{A IMPORTÂNCIA DO SE SENTAR EM RODA NA EDUCAÇÂO INFANTIL}

É importante notar que por intermédio do brincar em roda de conversação o professor pode despertar na criança habilidades a partir do compartilhamento de experiências de cada aluno, possibilitando o desenvolvimento da autonomia, da linguagem oral, da capacidade de expressividade, da resolução de conflitos, como também, despertar o senso de liberdade e responsabilidade dos discentes. Nesse sentido, o processo de socialização está vinculado tanto às experiências familiares como as escolares, proporcionando as crianças uma evolução dos aspectos sociais. 
Diante disso, salienta-se que "a roda assume a função essencial de desenvolvimento da autonomia, da liberdade como responsabilidade" (REAME [et al.] 2012, p.20).

Em referência às questões abordadas, o educador por meio da roda de conversação se torna o mediador na construção e ampliação do conhecimento, oportunizando o desenvolvimento da autonomia da criança. Essa autonomia pode ser instigada mediante a liberdade de se expressar do aluno perante a exposição de debate de suas experiências. A partir disso, o professor desperta na criança a aquisição de responsabilidade e através da conversa, o docente pode mapear a dificuldade dela frente à matemática.

Nesse contexto, o jogo é utilizado pelo professor para abordar diferentes temáticas, possibilitando melhor compreensão do aluno perante o conteúdo a ser trabalhado. Por exemplo, os jogos que envolvem soma e divisão, desencadeiam inúmeras formas de instituir o entendimento da criança. Diante do exposto, assinala-se que "Ao mesmo tempo a roda pode servir para a apresentação das instruções de um jogo e de suas regras" (REAME [et al.] 2012, pág.20).

Incube ao docente propor esse momento de interação entre as crianças por meio de algo muito presente na Educação Infantil, que é se sentar em roda, despertar nos discentes contatos diferenciados, no qual por meio do círculo podem ser propostas infinitas formas de se trabalhar com as crianças. Assim, algo simples do cotidiano escolar, como as rodas de conversação mediadas pelo docente, pode propiciar aos educandos uma melhor compreensão e interiorização dos conteúdos trabalhados. Nesse sentido,

Sentar em roda é privilégios da Educação Infantil, constituindo-se em espaço que favorece o autoconhecimento, o conhecimento do outro e das relações entre esses e o mundo que os rodeia. Nesse momento de interação, todos os integrantes do grupo podem se olhar, conversar de maneira informal, trocar idéias,contar novidades ou algum acontecimento que vivenciaram, enfim, participar de uma significativa atividade coletiva de comunicação de modo que todos possam expressar suas idéias, sentimentos, valores, desejos e compreender a expressão das idéias, sentimentos,valores e desejos do outro (REAME [et al.] 2012, p.19.)

Efetivamente, através da roda de conversação, o docente permite ao aluno uma junção entre capacidade de interpretação e imaginação - ludicidade, que se dá por meio do brincar, o que ocasiona uma ligação entre conhecer o outro como também conhecer o novo. 
É válido salientar que esse momento pode desenvolver no aluno capacidade de organização de tempo e espaço, bem como estimular a noção de quantidade por meio de dinâmicas que envolvam estratégias de resoluções de problemas.

Cabe sublinhar que a mediação desse trabalho com o apoio de estabelecimento de dinâmicas, o educando pode trazer diferentes estratégias, que tanto envolvam como despertem na criança conceitos de lateralidade, tempo, espaço e a percepção do outro.

\section{CONSIDERAÇÕES FINAIS}

A partir de tudo o que foi apresentado no presente texto pode-se concluir que, o ensino da matemática na Educação Infantil, é significativo para a construção da criança enquanto sujeito, haja vista todas as potencialidades que poderão ser desenvolvidas ao educando a partir do estudo dessa área do conhecimento, envolvendo conceitos, concepções, ideias, além do senso crítico e reflexivo do aluno.

Desse modo, o educador é extremamente importante por ser mediador na construção e ampliação dos conhecimentos, tendo a responsabilidade de oferecer estratégias de ensino ao educando, que estimule o desenvolvimento lógico-matemático através dos jogos, bem como a ludicidade que propicia momentos de brincar e brincadeiras com conteúdos expostos na roda de conversa, minimizando receios existentes entre aluno/professor.

Sendo assim, o ensino da matemática é substancial durante a formação das crianças que estão em um intenso processo de construção e reconstrução continua. É importante que o educador viabilize situações que conduzam os alunos a interagir com o meio, de forma a construir estruturas que favoreçam a aprendizagem de noções matemáticas desde o seu primeiro contato com o mundo que os cerca.

\section{REFERÊNCIAS BIBLIOGRÁFICAS}

\section{ALVES, Eva Maria Siqueira. A ludicidade e o Ensino de Matemática: Uma prática possível. Campinas: Papirus, 2001.}

CANAL, D. C. et al. O Ensino da Matemática Nos Anos Iniciais Numa Pespectiva Ludopedagógica. Canoas: ULBRA, 2013. Disponível em: $\langle$ http://www.conferencias.ulbra.br/index.php/ciem/vi/paper/viewFile/624/15 $>$. Acesso em: 10 de maio de 2017. 
GRADO, Regina Celia. O jogo e a matemática no contexto da sala de aula. São Paulo: Paulus, 2004.

KISHIMOTO, Tizuko Morchida (Org.). Jogo, brinquedo, brincadeira e a educação. 13. ed. São Paulo: Cortez, 2010.

MARANHAO, D.N.M.M. A importância do brincar e seu significado. Rio de Janeiro: WAK, 2004.

MARANHAO, D.N.M.M. Ensinar bricando: aprendizagem pode ser uma grande brincadeiraMente. 6. ed. São Paulo: Martins Fontes, 1998.

PINTO, Marly Rodan. Formação e aprendizagem no espaço lúdico: Uma abordagem interdisciplinar. São Paulo: Arte e ciência, 2003.

REAME.E [et al.]. Matemática no dia a dia da educação infantil: rodas, cantos, brincadeiras e histórias. São Paulo: Livraria Saraiva, 2012, p. 192.

SMOLE, K. S; DINIZ, M.I.; CANDIDO, P. Brincadeiras Infantis nas Aulas de Matemática. Porto Alegre: Artmed, 2000. 